\title{
Integrerade etiologiska analyser och drogprevention
}

\author{
PATRIK KARLSSON
}

\begin{abstract}
Vikten av etiologisk forskning lyfts ofta fram inom drogpreventionen. I artikeln diskuteras den centrala roll som en etiologisk syntes av två olika synsätt på ungdomars droganvändande skulle ha för att utveckla området. Förslag på upplägg på empiriska studier som testar detta diskuteras och centrala metodologiska aspekter berörs.
\end{abstract}

\section{Inledning}

Tanken om en evidensbaserad praktik (EBP) har inom flera områden mer eller mindre kommit att dominera diskussionen kring de interventioner som används. Diskussionen är helt klart viktig för inriktningen på ett område som till exempel socialt arbete (jfr Bergmark \& Lundström, 2006) och reser ett antal frågor som är svåra att bortse i från. Denna artikel kommer dock att ta ett steg tillbaka från interventionssidan och i stället fokusera på förståelsen av orsakerna till de problem som skall minskas via interventionerna, i detta fall med fokus på drogpre-

Patrik Karlsson, Universitetslektor, institutionen för socialt arbete, Stockholms universitet. ventionsområdet (prevention av alkoholoch narkotikakonsumtion). Artikelns syfte är: 1) att diskutera behovet av och möjligheten till teoretisk integration av två övergripande, men olika, synsätt på alkohol- och narkotikaanvändning bland ungdomar, 2) ge några preliminära, generella förslag på hur empiriska studier som testar detta kan riktas in och struktureras, samt 3) att diskutera centrala metodologiska apsekter att beakta vid empiriska tester av integrerade modeller.

Inom drogpreventionen har det visat sig svårt att uppnå effektiva interventioner. Nyligen har det framkommit att programmet Iowa Strenthening Families Program - vilket får stöd i en ny forskningsöversikt från Cochrane Collaboration om familjeprogram mot alkoholkonsumtion bland 
ungdomar (Foxcroft \& Tsertsvadze, 2011) - i en svensk version inte har några effekter på alkohol-, tobaks- och narkotikakonsumtion bland svenska ungdomar (Skärstrand, 2010). Ett annat program, Örebro Prevention Program (ÖPP), som i tidigare studier visat sig kunna minska ungdomars berusningsdrickande (Koutakis et al., 2008) framträder som ineffektivt $i$ en senare studie (Bodin \& Strandberg, 2011). Internationellt har flera av utvärderingarna av de program som anses mest effektiva, visat sig behäftade med metodologiska problem som allvarligt minskar deras tillförlitlighet (se t ex Gorman, 2005). Det kan således finnas grund för att ta ett steg tillbaka för att på så sätt på sikt kunna öka precisionen hos de interventioner som syftar till att minska alkohol- och narkotikaanvändandet bland ungdomspopulationen.

\section{Olika synsätt}

I likhet med andra interventionsområden bygger drogpreventionen på mer eller mindre genomtänkta idéer kring vilka de förmodade orsakerna är till de problem man skall minska, ett antagande som inom området har formulerats som "lagen om indirekta effekter" (Hansen \& McNeal, 1996). Den enkla logiken är att man riktar in interventioner på de förmodade orsakerna (t ex familjekonflikter, psykiska besvär), vilket i sin tur förmodas minska det aktuella problemet ( $\mathrm{t}$ ex alkoholkonsumtion). Inom drogpreventionen spelar följaktligen forskning om orsaker (etiologisk forskning) till de problem som man vill förebygga en central roll.
Inom den forskning som på ett eller annat sätt intresserar sig för varför ungdomar använder droger (alkohol och narkotika) kan en grov skiljelinje dras mellan en tradition som ger fenomenet en mer"patologisk" inramning och en tradition som snarare ser det som något "normalt", "ickepatologiskt". Att synsätten framträder som distinkta från varandra förstärks inte minst av att relativt få forskare har försökt att syntetisera dessa (se dock Measham \& Shiner, 2009 för en diskussion om möjligheten att förena det senare synsättet med den kritik som riktats mot detsamma samt referenser till andra analyser om detta).

Den första forskningstraditionen är till stor del inramad av en sorts "bristmodell" (för denna slutsats, se Karlsson, 2006; Rhodes et al., 2003; se också Mugford, 1994; Parker, 2003) och har träffande nog beskrivits som "det patologiska paradigmet" (Mugford, 1991, citerad i Moore, 2008, s. 353). Ungdomar utan psykologiska, familjemässiga eller andra brister antas omvänt vara mindre benägna att använda droger. Droganvändandet ses därmed i avvikande termer: droganvändande ungdomar skiljer sig från andra ungdomar och preventionens uppdrag blir att motverka dessa brister via exempelvis skol- eller familjebaserade insatser. Synsättet har utmanats av en växande forskning kring så kallat rekreationellt droganvändande (den andra traditionen), där mycket av forskningen koncentrerats till narkotikakonsumtion. En välkänd företrädare är Howard Parker, som tillsammans med sina kollegor under 1990talet utvecklade en "normaliseringstes" beträffande ungdomars narkotikaanvändande (se t ex Parker et al., 1998). Ett fler- 
tal empiriska studier har bedrivits som på ett eller annat sätt utgår ifrån, testar eller förfinar tesen (se t ex Duff et al., 2012; Järvinen \& Demant, 2011; Pennay \& Moore, 2010; Smith et al., 2011).

I en Editoral i Addiction Research \& Theory beskriver Parker (2003) hur förvånad han själv blivit av resultaten från de panelstudier som han genomfört bland engelska ungdomar sedan början av 1990-talet. Han menar vidare att detta reser frågetecken kring den "traditionella" förståelsen på området. Parker och hans medarbetare fann att merparten av de droganvändande ungdomarna var förvånansvärt" anpassade". De har sökt förklara narkotikakonsumtion bland dagens ungdomar med hänvisning till delar av den moderna sociologiska teoribildningen kring sen- och postmodernitet (med fokus på aspekter som individualisering, konsumtion, osäkerhet, risk, förändrade uppväxtvillkor etc, se t ex Parker et al., 1998, kap 1) och Parker hävdar i nämnda editoral bestämt att "rational consumtion theory is more convincing than 'vulnerability' to substance use" (Parker, 2003, s. 143). Parker och medarbetare betonar därmed att det finns ett rationellt inslag i narkotikakonsumtionen, som de menar ofta kan förklaras på liknande sätt som andra beteenden (Parker et al., 1998, s. 158).

Parker och kollegor har med sin normaliseringstes bidragit med teoretiskt inflöde till forskningen om ungdomars alkohol-och narkotikaanvändning (även om det är det senare som är deras huvudfokus). En risk med synsättet är att den konsumtionslogik som sägs prägla droganvändandet överdrivs. Det pågår emellertid en aktuell, men än så länge begränsad, diskussion om hur man kan "uppdatera" normaliseringstesen för att $t$ ex korrigera dess väl individualistiska fokus (se t ex Duff et al., 2012; Measham \& Shiner, 2009). Ett intressant bidrag är en artikel av Measham och Shiner (2009), där den förra var med och lanserade normaliseringstesen och den senare fört fram kritik mot den. I artikeln presenteras likheter och skillnader i författarnas respektive synsätt. En av skiljepunkterna gäller just hur man skall se på droganvändning bland dagens ungdomar där den ene talar "in terms of unprecendented change resulting in a radical break from the past...while the other maintains that there are important elements of continuity" (Measham \& Shiner, 2009, s. 506). Measham och Shiners försök är viktigt, men de visar lite intresse för att inkorporera individuella "bristfaktorer" och utan att någon substantiell argumentation egentligen förs kring rimligheten av att göra denna uteslutning (relevansen av individuella bristfaktorer avfärdas kort mer eller mindre i förbifarten). Detta är en begränsning eftersom empirisk forskning visar på en rad individuella och andra riskfaktorer för droganvändning (se Hawkins et al., 1992; Rhodes et al., 2003 för översikter).

En viktig aspekt här är att prospektiva studier visar att flera riskfaktorer för droganvändning de facto varit stabila över lång tid (Brown et al., 2001). Tillsammans med en ökning av rekreationella konsumtionsmotiv över tid (Palmqvist et al., 2003) ger detta för handen att tillfredsställande förklaringar troligtvis bör beakta både "gamla" och "nya" faktorer (jfr Measham \& Shiner, 2009, s. 503). Det är därför av betydelse att försöka göra en "syntes" av "traditions- 
bunden" respektive "modern" forskning om ungdomar och droger (Karlsson, 2006).

Nedan diskuteras utfirån Flay och Petraitis (1994) teori om triadiskt inflytande (Theory of Triadic Influence) ett preliminärt förslag på hur detta kan göras. Tesen är, utifrån detta teoretiska ramverk, att en del oförenligheter mellan perspektiv på droganvändandet eventuellt kan förklaras av att de har fokus på olika kausala "nivåer", dvs. de fokuserar på orsaker som befinner sig olika långt bort från de utfallsvariabler som analyseras (jfr Lieberson \& Lynn, 2002, s. 11-12) och att detta bör prövas innan de slutgiltigt ses som oförenliga. Diskussionen tar också fasta på en del lärdomar som kan dras ifrån forskning om de motiv som människor har till att konsumera droger (varav merparten fokuserar på alkohol) och de bakomliggande faktorer som formar dessa (se t ex Kuntsche et al., 2006). Inom denna forskning finns en ambition att studera hur olika konsumtionsmotiv korrelerar med konsumtion, men också hur exempelvis diverse personlighetsfaktorer formar dessa motiv. Även om det (enligt min kännedom) inte utryckts på detta sätt kan den generella inriktningen på denna forskning till viss del ses som en överbryggning av de två grundläggande synsätten.

\section{Hur göra? Några preliminära förslag}

Flay och Petraitis (Flay \& Petraitis, 1994) teori om triadiskt inflytande - vilken av dem beskrivs som "integrativ" - ger för handen att droganvändning och andra hälsobeteenden formas av tre övergripande "strömmar av inflytanden" ("streams of influence"): 1) "den kulturella/attitudinella strömmen" ("cultural/attitudinal stream") 2) "den sociala/normativa strömmen" ("social/ normative stream") samt 3) "den intra-personella strömmen" ("intra-personal stream"). ${ }^{1}$ Var och en av dessa tre "strömmar" sägs vidare innefatta en uppsättning kausala faktorer som befinner sig på olika avstånd från det utfall som skall förklaras (t ex. droganvändning). De olika nivåerna benämns 1) "ultimata orsaker" ("ultimate causes") 2) "avlägsna orsaker" ("distal causes") samt 3) "närliggande bestämningsfaktorer" ("proximal predictors"). Varje "ström" består alltså av kausala faktorer på olika distans från utfallet. I den kulturella/attitudinella strömmen, till exempel, beskrivs den övergripande socio-kulturella miljön som en "ultimat orsak" medan variabler som kunskaper, förväntningar och värderingar ligger närmare beteendet i fråga. Modellen specificerar dock också kausala effekter tvärs över de tre "strömmarna" av inflytande (se mer nedan).

Flay och Petratis (1994) teori är användbar för att organisera empiriska resultat, samt mindre omfattande teorier, i förhållande till varandra. Författarna har på annat håll visat att teorin kan syntetisera flera teorier kring droganvändning bland ungdomar (Petraitis et al., 1995). Genom

1 Idén om tre sorters inflytande sägs uttryckligen ha sin motsvarighet i de tre begreppen "miljö" (environment), "situation" och "person" och som av Albert Bandura och andra teoretiker tidigare lyfts fram som centrala i analyser av mänskligt beteende (Flay \& Petraitis, 1994, s. 22; Flay et al., 2009, s. 453). 
att vara tydlig beträffande de kausala relationer som förmodas ligga bakom ett beteende som droganvändning är den också empiriskt testbar. I Flay et al. (2009) ges en ännu tydligare beskrivning av de kausala relationer som teorin specificerar samt en översikt av studier som testat dessa empiriskt.

Teorins uppdelning av tre olika "strömmar" förefaller användbar i försök att syntetisera de två olika forskningslinjer som diskuteras här. Forskningen om rekreationell droganvändning befinner sig huvudsakligen i den första "strömmen". Förklaringen till ungdomars droganvändning söks till stor del i en starkt konsumtionsinriktad kultur och i ett förändrat samhälle i stort (Parker et al., 1998), det vill säga en sociokulturell aspekt (den "ultimata orsaken" i den första "strömmen" enligt teorin om triadiskt inflytande). Denna forskning är vidare förenlig med denna ström, då man betonar rationella "nyttobedömningar"("cost-benefit assessment") som grund för droganvändandet (se t ex Parker et al., 1998, s. 132ff). Denna beskrivs som en "närliggande" ("proximal") variabel inom den "kulturella/ attitudinella strömmen" i teorin om triadiskt inflytande (se Petraitis et al., 1995, tabell 1, s. 82). Den sociokulturella miljöns inflytande på ungdomars droganvändning kan alltså utifrån denna teori förväntas medieras längre fram i den kausala kedjan av en bedömning av för- och nackdelar med att använda droger (Flay \& Petraitis, 1994). Teorin specificerar en tydlig kausal koppling mellan den information och de värderingar som florerar i ungdomars sociokulturella miljö och de uppfattningar som de formar i förhållande till droganvändning och andra hälsobeteenden (Flay \& Petraitis, 1994; Flay et al., 2009).

Den "traditionella forskningen", å andra sidan, rör sig i stor utsträckning i den andra ("den sociala/normativa strömmen") och tredje "strömmen" ("den intra-personella strömmen"). I den tredje strömmen återfinns, till exempel, de psykologiska riskfaktorer som mycket av den traditionsbundna forskningen studerar. Centralt i sammanhanget är dock att samtliga tre sorters inflytanden längre ner i den kausala kedjan går via variabeln "decisions/intentions", dvs. ungdomars beslut att konsumera färgas av inflytanden från samtliga tre "strömmar" (Flay \& Petraitis, 1994; Flay et al., 2009).

En fördel med teorin i förhållande till integrerade etiologiska analyser är att den pekar på de begränsningar som olika synsätt i sig är förenade med. Det är rimligt att anta att den sociokulturella miljön influerar droganvändandet, men bara så länge man är medveten om att detta är $e n$ del av förklaringen. Detsamma gäller för de "bristfaktorer" som annan forskning identifierat. Genom att dela upp dessa kategorier av kausala faktorer i olika sorters inflytanden, är det möjligt att göra en preliminär syntes av dessa forskningslinjer. Denna kan sedan testas empiriskt.

Flay och Petraitis (1994) modell specificerar även att effekter kan gå tvärs över de tre övergripande "strömmarna" ("interstream pathways", s. 36). Detta, kopplat med deras idé om kausala effekter på olika nivåer, kan ses som en viktig utgångspunkt för empiriska tester av förutsättningarna till teoretisk syntes av de två olika forskningslinjerna. En konsekvens av modellen är att empiriskt stöd för en modell inte nöd- 
vändigtvis innebär att en annan modell inte har stöd. För att ge ett exempel. Anta att en studie visar att individer som vid tidpunkt T1 kopplar samman narkotikakonsumtion med njutning vid tidpunkt $T 2$ är mer benägna att konsumera, än de som vid $T 1$ inte gjorde denna koppling. Detta hypotetiska resultat är i linje med en studie av Lee et al. (2007, s. 1388-1389) där det framgick att "enjoyment/fun" är den vanligaste motivkategorin till marijuanaanvändning bland unga vuxna amerikaner (njutning och "enjoyment/fun" bör kunna ses som snarlika). Njutning är ett typiskt rekreationellt motiv och detta hypotetiska resultat skulle därmed kunna ses som stöd för den "moderna" forskningen om droganvändning. Resultaten falsifierar emellertid inte nödvändigtvis det andra synsättet; det kan tvärtom vara fullt förenligt med detta.

Det kan mycket väl vara så att det finns ett samband mellan att tro att man skulle njuta av att använda narkotika och någon "bristfaktor" och att den senare tidsmässigt föregår den förra. Vissa "bristfaktorer" kan ha en effekt på ett motiv som "njutning" vilket i sin tur påverkar konsumtionen. Inom alkoholområdet specificerar så kalllade motivationsmodeller att dryckesmotiv är den variabel som kausalt sett ligger närmast utfallet (alkoholkonsumtion) och där effekten av mer kausalt avlägsna faktorer går via dessa motiv (se t ex Kuntsche et al.,
2005 s. 842-844). I exemplet ovan skulle alltså motivet njutning kunna mediera effekten av en mer avlägsen variabel, vilket illustreras i figur 1.

Flera tänkbara kandidater för bristfaktorn i figur 1 kan nämnas. I Rhodes et al. (2003, s. 308) beskrivs en rad individuella faktorer som tidigare forskning visat relaterade till narkotikaanvändning, som bland annat alienation, aggression, inhibition (ung. grad av "hämning"), sensationssökande, låg självkänsla och "icke-konventionalitet" (unconventionality). Utifrån tillgänglig kunskap inom alkoholområdet kan vissa av dessa förväntas vara kopplade till narkotikaanvändning i njutningssyfte. Så har faktorer som högt sensationssökande, bristande "plikttrogenhet" (conscientiousness) och begränsad förmåga att hantera aggression kopplats till den typ av dryckesmotiv som i motivlitteraturen kallas för "enhancement motives" (ung. "förhöjning") (se Kuntsche et al., 2006 för en forskningsöversikt) och som har en likande innebörd som njutningsmotivet. Sensationssökande har också ett samband med "enhancement motives" i förhållande till marijuanakonsumtion (Simons et al., 2005). Detta skall inte tolkas som att bristfaktorer enbart är relaterade till konsumtion via "enhancement motives". Forskning kring såväl alkohol- som marijuanakonsumtion visar $t$ ex att av vissa bristfaktorer är kopplade till s.k.

\section{Figur I.}

Hypotetisk modell över hur en kausalt "avlägsen" bristfaktor påverkar narkotikaanvändning.

$$
\text { BRISTPARTOR } \Rightarrow \text { NJUTNING } \Rightarrow \text { NARROTIRAANVÅNDNING }
$$


"coping-motiv" (Bonn-Miller et al., 2007; Kuntsche et al., 2006; Simons et al., 2005).

I figur 2 ges ytterligare en illustration (av många tänkbara) på en modell som skulle kunna användas vid tester av teoretisk syntes av den traditionella respektive moderna drogforskningen utifrån Flay och Petraitis (1994) ramverk. Som nämndes ovan söker forskningen om rekreationell droganvändning, i Parker och medarbetares tappning (Parker et al., 1998), en stor del av förklaringen till ungdomars användning av alkohol och övriga droger i dagens konsumtionssamhälle. Detta konsumtionssamhälle kan likställas vid en sociokulturell aspekt (se figur 2). Ett annat antagande är att individen fattar beslut om droganvändande på basis av en rationell värdering av för- och nackdelar, vilket också lyfts fram som ett problem då mer "strukturella faktorer" underbetonas (se Measham \& Shiner, 2008, s. 504-505). Denna forskningstradition specificerar emellertid sällan om den socio-kulturella miljön kan tänkas forma andra kausalt mer närliggande inflytanden.

Figur 2 visar ett exempel på en tänkbar riskfaktor, eller snarare en riskfaktordomän, varigenom effekten av den sociokulturella miljön kan tänkas gå. Det är välkänt att familjerelaterade faktorer formar ungdomars alkohol- och narkotikavanor (se t ex Velleman et al., 2005 för en översikt). Familjestruktur är ett exempel på en sådan faktor som är relaterad till droganvändning, där ungdomar med frånskilda föräldrar är i riskzonen (se t ex Barrett \& Turner 2006; Ledoux et al., 2002). Flera familjefaktorer kan emellertid förmodas påverkas av andra bakomliggande faktorer, såsom den sociokulturella miljön. Spooner (2005) riktar uppmärksamheten mot att vad hon benämner "family functioning", sannolikt påverkas av övergripande sociala faktorer. Stress relaterad till förhöjd arbetsbelastning och mer osäkra anställningsförhållanden är två exempel som lyfts fram.

Det är dock inte enbart "bristfaktorer" inom familjedimensionen som kan tänkas påverkas av denna övergripande faktor. Eckersley (2005) pekar på att den konsumtionsdrivna kultur som Parker och andra forskare tillskriver så stor vikt (Parkers forskning nämns dock inte i artikeln), något paradoxalt kan ge upphov till den typ av individuella bristfaktorer som den traditionsbundna forskningen fokuserar på. Han hävdar med stöd i tidigare studier att den är kopplad till aspekter som ångest, depression och alienation (Eckersley, 2005, s. 159). Dessa kan ses som typiska bristfaktorer på individnivån. Huruvida samhällsförändringar de facto påverkar personlighetsegenskaper hos ungdomar är dock en omdebatterad fråga (se Trzesniewsky \& Donellan, 2010; Twenge \& Campbell, 2010 för två olika synsätt).

\section{Figur 2.}

Hypotetisk modell över hur den socio-kulturella miliön påverkar droganvändning.

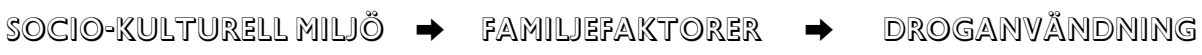




\section{Integrerad etiologisk analys och empiriska studier: exemplet"mediation" och "confounding"2}

Flay och Petraitis (1994) teori om triadiskt inflytande specificerar teoretiskt att det finns orsaker på olika "avstånd" från utfallet och att mer avlägsna faktorer påverkar utfallet via mer närliggande faktorer. De senare fungerar därmed som mellanliggande variabler, en aspekt som är mer elaborerad i senare framställningar av teorin och där mer empiriskt stöd presenteras för detta (Flay et al., 2009). Att effekten av de mer avlägsna faktorerna beskrivs som indirekt har inte enbart en teoretisk betydelse. Det får också implikationer för konkreta kvantitativa analyser av samband med hjälp av multipla analysmetoder och de slutsatser som dras från dessa beträffande stödet för olika teoretiska synsätt.

Mycket av forskningen på området ("riskfaktorforskning") är empiristisk (jfr Gernstein \& Green, 1993), där principen ofta är att med hjälp av multivariata tekniker identifiera riskfaktorer. Oetting och Donnermeyer (1998) påtalar träffande att dessa studier begränsar sig till att visa upp en slags "menyer av risk- och skyddsfakto-

2 Jag har i texten valt att använda de engelska termerna för dessa två, snarare än svenska översättningar, då jag inte känner till några svenska motsvarigheter som tillfullo återger deras innebörd. Enligt Norstedts stora engelska ordbok är en svensk översättning av mediate, t ex "ett mellanled" eller"en mellanlänk" medan confound enligt samma ordbok kan översättas som "blanda samman" eller "förväxla". rer" (s. 997). En risk med förfarandet är, till exempel, att tveksamma tolkningar $i$ vissa situationer kan göras av icke-signifikanta samband - något som får konsekvenser för vilka slutsatser som dras. Denna basala aspekt är viktig att beakta när det gäller empiriska modeller som inkluderar faktorer från såväl "traditionell" som "modern" forskning om ungdomar och droger då dessa faktorer ofta kan förväntas befinna sig på olika avstånd från utfallet och ibland också i samma kausala kedja (jfr Flay \& Petraitis [1994, s. 36] idé om "interstream pathways"). I detta fall kan en minskning av effekten av en kausalt mer avlägsen faktor på utfallet, vid kontroll för en kausalt mer närliggande variabel i samma kausala kedja, ses som stöd för en s.k. indirekt eller medierad effekt (jfr Baron \& Kenny, 1986).

Det resonemang som förs här gällande tolkning av icke-signifikanta samband i tester av integrerade modeller gäller multivariata analyser och inte bivariata dito (där den typ av tveksamma tolkningar som diskuteras nedan knappast kan göras). Diskussionen bygger emellertid på att det finns ett statistiskt signifikant bivariat samband mellan en oberoende variabel $\boldsymbol{X}$ och en beroende variabel $\boldsymbol{Y}$ men som försvinner i en multivariat modell där en tredje variabel $\boldsymbol{Z}$ kontrolleras. Diskussionen illustreras med hänvisningar till forskning som studerar inverkan av familj och kamrater på droganvändning bland ungdomar - ett område där det finns både empiriska resultat och teoretiska analyser som är direkt relevanta för den aktuella diskussionen.

En lika grundläggande som central utgångspunkt här är att sk. confounding och sk. mediation, vilka visas i undre respektive 
övre delen av figur 3 på det sätt som dessa ofta presenteras grafiskt (se t ex Bernstein \& Dyer, 1992, s 205 \& 209), är teoretiskt olika men statistiskt sett likartade (Christenfeld et al., 2004; MacKinnon, et al., 2000). Att en oberoende variabel $\boldsymbol{X}$ har en ickesignifikant effekt på en beroende variabel $\boldsymbol{Y}$ i en multivariat analys innebär alltså inte automatiskt att den är orelaterad till utfallet. Bortser man från att en tredje variabel $\boldsymbol{Z}$ kan mediera sambandet mellan $\boldsymbol{X}$ och $\boldsymbol{Y}$ och sambandet mellan $\boldsymbol{X}$ och $\boldsymbol{Y}$ blir icke-signifikant (eller minskar kraftigt) vid kontroll för $\boldsymbol{Z}$ kan tolkningen av resultaten bli mycket tveksam (jfr Christenfeld et al., 2004) ${ }^{3}$.

Ett enkelt exempel kan få illustrera resonemanget. En studie genomförs för att analysera sambandet mellan en indikator på familjerelationer $\boldsymbol{X}$ och droganvändning $\boldsymbol{Y}$. I en första modell studeras det bivariata sambandet mellan dessa, vilket är signifikant. I en andra modell kontrolleras för en indikator på hur många droganvändande kamrater $\boldsymbol{Z}$ ungdomarna har. När detta görs blir sambandet mellan familjevariabeln och droganvändning icke-signifikant. Exemplet är varken unikt eller taget ur luften: Warr (1993) har visat på just sådana mönster $i$ en studie om brottslighet (delinquency) där

3 Saker och ting blir mer komplicerade om en tredje variabel $\mathbf{Z}$ över tid fungerar som både en confounder och som en mediator eftersom man då så att säga både måste kontrollera för variabeln eftersom den är en confounder, samtidigt som det inte är tillrådigt att göra detta för medierande variabler om man vill skatta storleken av effekten av $\mathbf{X}$ på $\mathbf{Y}$ (Robins et al., 2000). S.k. Marginal Structural Models har lyfts fram som en lösning på detta uppenbara problem (Robins et al., 2000). samtliga bivariata samband mellan anknytning till föräldrar och brottslighet blir ickesignifikanta (och där koefficienterna minskar kraftigt i omfattning) vid kontroll för "brottsliga vänner" ("delinquent friends") (se tabell 6, s. 259). (Warrs tolkning av sambandet är att "brottsliga vänner" medierar effekten av familjeanknytning. Detta är i linje med den andra tolkning som nedan görs av det hypotetiska exemplet.)

En tolkning är att familjevariabeln inte är av betydelse för droganvändandet eftersom den inte är statistiskt signifikant när den andra variabeln kontrolleras (en tolkning som representeras av den undre modellen i figur 3). I studier där flera oberoende variabler inkluderas i samma steg och utan att den empiriska analysen baseras på en teoretisk, kausal modell torde denna tolkning vara relativt vanlig. Teoretiskt kan dock en annan tolkning göras av varför sambandet inte längre är signifikant. Denna är att sam-

\section{Figur 3.}

Två olika kausala modeller som kan förklara varför sambandet mellan $\boldsymbol{X}$ och $\boldsymbol{Y}$ inte är statistiskt signifikant vid kontroll för $\boldsymbol{Z}$ (Christenfeld et al., 2004; MacKinnon et al., 2000). Den översta modellen illustrerar "mediation", den understa illustrerar "confounding".

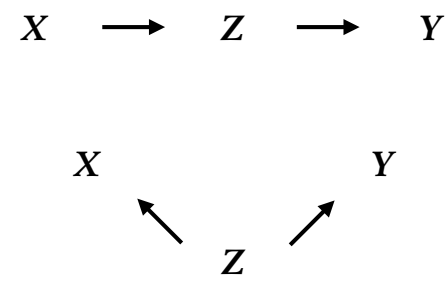

Patrik Karlsson: Integrerade etiologiska analyser och drogprevention 
bandet mellan familjevariabeln och droganvändandet medieras av variabeln droganvändande kamrater (kvaliteten på familjerelationerna påverkar val av kamrater vilket påverkar konsumtionen, det är alltså utifrån ett preventionsperspektiv viktigt att påverka familjerelationerna). Detta representeras av den övre modellen i figur 4. Henry (2008) har i en empirisk prövning av (delar av) Oetting och Donnermeyer's (1998) Primary Socialization Theory påvisat en kausal kedja där bristande familjeanknytning vid $T 1$ är kopplat till bristande anknytning till skolan ("school attachment") vid T2, vilket i sin tur är kopplat till involvering ("involvement") med droganvändande kamrater vid $T 3$, och där den senare är relaterad till droganvändning vid fjärde mättillfället (T4).

Henrys (2008) slutsats är att bristfällig familjeanknytning till betydande del paiverkar droganvändning via dess effekt på skoloch kamratfaktorer (dvs. dessa två medierar effekten av den förra) och att unga människors familjeanknytning därför är en betydelsefull faktor. Utan studiens teoretiska inramning skulle slutsatsen kunna dras att eftersom "effekten" av anknytning minskas vid kontroll för anknytning till skolan samt involvering med kamrater, är det viktigt att justera för de senare för att undvika felaktiga skattningar av betydelsen av familjeanknytning. Detta är en annorlunda slutsats beträffande relationen mellan dessa tre faktorer än den som Henry (2008) presenterar.

Det har påtalats att kamraters inverkan på ungdomars droganvändning ofta har överskattats bland annat på grund av att man inte beaktat selektion $\mathrm{i}$ studier av sambandet mellan kamraters konsumtion och ungdomars egen konsumtion av alkohol/ narkotika/tobak (se t ex Bauman \& Ennett, 1996; Kandel, 1996 för denna slutsats). Flera studier bekräftar vikten av att beakta selektion för att förklara sambandet $(\mathrm{t}$ ex de Vries et al., 2006; Poulin et al., 2011; Simons-Morton, 2007). När det gäller fokus i denna artikel finns det dock en viktigare aspekt att beakta här: om man bortser från att variabeln droganvändande kamrater kan mediera sambandet mellan familjefaktorer och droganvändning (vilket Henrys resultat ger stöd för, se också Engels et al., 2004; Kandel, 1996; Warr, 1993) finns det en risk att familjefaktorns inverkan underskattas i multivariata analyser där både dessa variabler inkluderas. ${ }^{4}$ Kandel (1996) har omvänt pekat på att kamratvariabelns inflytande kommer att överskattas och föräldrars inflytande att underskattas om man inte tar hänsyn till att den senare påverkar ungdomars val av kamrater.

Samma resonemang är relevant för studier med integrerande ambitioner där exempelvis olika familjevariabler ( $t$ ex bristande anknytning) kan tänkas inkluderas tillsammans med indikatorer på $\mathrm{t} \mathrm{ex}$ njutningsrelaterade motiv $i$ en multivariat modell med droganvändning som utfallsvariabel. Det kan t ex kopplas till den hypotetiska modell som presenteras i figur 1 (bristfaktor $\rightarrow$ njutning $\rightarrow$ narkotikaanvändning) och där vi nu utgår från att "bristfaktorn"

4 Det finns tecken på att sambandet mellan familje- och kamratvariabler kan vara "dynamiskt" över tid, dvs, snarare än att effekten enbart går åt ett håll så påverkar dessa variabler varandra (Dishion et al., 2004). Detta får konsekvenser för hur man bör behandla tredje variabler i empiriska studier, jfr not 3 . 
avser bristande anknytning till föräldrar. Om bristfaktorn påverkar motivet "njutning" och om effekten av bristfaktorn på narkotikaanvändning försvinner vid kontroll för variabeln njutning och den senare har en effekt på utfallet ("perfekt mediering", se Baron \& Kenny, 1986, s. 1177; jfr också Flay et al., 2009, s. 468), är det alltså mycket tveksamt att säga att enbart njutning är relaterad till narkotikaanvändning (dvs. stöd för den "moderna" drogforskningen) men att bristfaktorn inte är det (dvs. ej stöd för den "traditionella" drogforskningen).

\section{Slutsats}

I denna artikel har en preliminär diskusison först om hur man skulle kunna gå tillväga för att testa möjligheten till integration av två olika synsätt på droganvändning bland ungdomar. Artikeln pekar på relevansen av ett tydligt teoretiskt perspektiv på kausala samband i empirisk, etiologisk drogforskning med integrerande ambitioner. Utifrån en sådan infallsvinkel är det möjligt att vad som först verkar vara tydliga motsättningar mellan olika synsätt, vid närmare granskning inte behöver vara det. Fördelarna med teoretiskt styrd kvantitativ forskning $\mathrm{i}$ allmänhet har lyfts fram många gånger - ambitionen har inte varit att peka på detta än en gång. Fokus har i stället varit att specifikt rikta uppmärksamheten på behovet av ordentligt "teoretiskt förarbete" (och "efterarbete") vid empiriska tester av modeller som integrerar såväl "traditionell" som modern forskning om ungdomar och droger. Detta gäller oavsett om testerna görs på tvärsnitts- eller longitudinella data.
Det är naturligtvis önskvärt att data i etiologiska analyser är av så god kvalitet att den typ av potentiella, medierade effekter som diskuterats här, kan testas adekvat $\mathrm{i}$ integrerade analyser. Ofta är dock detta inte fallet. Även i situationer när data är av mindre önskvärd kvalitet (tvärsnitt) är det viktigt att ha ett teoretiskt rimligt upplägg på modellerna. Detta inte minst med tanke på de problematiska tolkningar som annars lätt kan göras av icke-signifikanta samband och vilket kan leda till missvisande rekommendationer till praktiken.

Ett komplement till det förslag på empiriska prövningar som skisserats i denna artikel är att testa olika teoretiska modeller i subgrupper. Moffitt (1993) hävdar i en inflytelserik artikel att två grupper av individer ansvarar för vad som benämns som normbrytande beteenden, där den ena kallas "adolescence-limited" och den andra "lifecourse persistent". Moffitts poäng är att båda grupperna ägnar sig åt normbrytande beteende under ungdomsåren, men att detta för den förra gruppen (vilken beskrivs som utan tvekan störst), är något övergående till skillnad från vad som är fallet i den andra gruppen. Moffitts (1993) teori om två grupper av normbrytande ungdomar nämns också av Parker och medarbetare som stöd för deras synsätt (Parker et al., 1998).

Denna idé bygger på andra utgångspunkter - respektive grupp som distinkt från den andra - än de som diskuterats här Det kan eventuellt finnas fördelar med att i ett första led testa giltigheten av mer integrerade modeller, för att senare göra mer detaljerade analyser inom subgrupper i syfte att öka precisionen hos de teoretiska modellerna. 


\section{Referenser}

Baron, R.M., \& Kenny, D.A. (1986). The moderator-mediator variable distinction in social psychological research: conceptual, strategic, and statistical considerations. Journal of Personality and Social Psychology, 51 (6), 1173-1182.

Barrett, A.E., \& Turner, R.J. (2006). Family structure and substance use problems in adolescence and early adulthood: examining explanations for the relationship. Addiction, 101, (1), 109120.

Bauman, K.E., \& Ennett, S. (1996). On the importance of peer influence for adolescent drug use: commonly neglected considerations. Addiction, 91 (2), 185-198.

Bernstein, R.A., \& Dyer, J.A. (1992). An introduction to political science methods. Englewood Cliffs, New Jersey: Prentice-Hall .

Bergmark, A., \& Lundström, T. (2006). Mot en evidensbaserad praktik.? Om färdriktningen i socialt arbete. Socialvetenskaplig Tidskrift, 13 (2), 99-113.

Bodin, M.C., \& Strandberg, A.K. (2011). The Örebro prevention programme revisited: a cluster randomized effectiveness trial of programme effects on youth drinking. Addiction, 106, (12), 2134-2143.

Bonn-Miller, M.O., Zvolensky, M.J., \& Bernstein, A. (2007). Marijuana use motives: Concurrent relations to frequency of past 30-day use and anxiety sensitivity among young adult marijuana smokers. Addictive Behaviors, 32 (1), 49-62.

Brown, T.N., Schulenberg, J., Bachman, J.G., O'Malley, P.M., \& Johnston, L.D. (2001). Are risk and protective factors for substance use consistent across historical time? National data from the school classes of 1976 through 1997. Prevention Science, 2, (1), 29-43.

Christenfeld, N.J.S., Sloan, R.P., Caroll, D., \& Greenland, S. (2004). Risk factors, confounding, and the illusion of control. Psychosomatic Medicine, 66, (6), 868-875.

de Vries, H., Candel, M., Engels, R., \& Mercken, L. (2006). Challenges to the peer influence para- digm: results for 12-13 year olds from six European countries form the European smoking prevention framework approach study. Tobacco Control, 15, (2), 83-89.

Dishion, T.M., Nelson, S.E., \& Bullock, B.M. (2004). Premature adolescent autonomy: parent disengagement and deviant peer process in the amplification of problem behavior. Journal of Adolescence, 27, (5), 515-530.

Duff, C., Asbridge, M., Brochu, S., Cousineau, M-M., Hathaway, A.D., Marsh, D., Erickson, P.G. (2012). A canadian perspective on cannabis normalization among adults. Addiction Research \& Theory, 20 (4), 271-283.

Eckersley, R.M. (2005). 'Cultural fraud': the role of culture in drug abuse. Drug and Alcohol Review, 24(2), 157-163.

Engels, R.C.M., Vitaro, F., Den Exter Blokland, E., de Kemp, R., \& Scholte, R.H.J. (2004). Influence and selection processes in friendship and adolescent smoking behaviour: the role of parental smoking. Journal of Adolescence, 27, (5), 531-544.

Flay, B.R., \& Petraitis, J. (1994). The theory of triadic influence: a new theory of health behavior with implications for preventive interventions. I G.S. Albrecht (ed.), Advances in medical sociology, Vol. IV: A reconsideration of models of health behavior change (sid 19-44). Greenwich, CT: JAI Press.

Flay, B.R., \& Snyder, F., \& Petraitis, J. (2009). The Theory of Triadic Influence. I R.J. Climente, M.C. Kegler \& A. Crosby (eds.). Emerging theories in health promotion practice and research (sid 451-510). New York: Jossey-Bass.

Foxcroft, D.R., \& Tsertsvadze, A. (2011). Universal family-based prevention programs for alcohol misuse in young people. Cochrane Database of Systematic Reviews, nr 9, artikelnr. CD009308.

Gernstein, D., \& Green, L. (1993). Preventing drug abuse: what do we know? Washington: National Academy Press. 
Gorman, D.M. (2005). Drug and violence prevention: Rediscovering the critical rational dimension of evaluation research. Journal of Experimental Criminology, 1, (1), 39-62.

Hansen, W.B., \& McNeal, R.B. (1996). The law of maximum expected effect: constrains placed on program effectiveness by mediator relationships. Health Education Research, 11 (4), 501-507.

Hawkins, D.J., Catalano, R.F., \& Miller, J.Y. (1992). Risk and protective factors for alcohol and other drug problems in adolescence and early adulthood: implications for substance abuse prevention. Psychological Bulletin, 112 (1), 64-105.

Henry, K. (2008). Low prosocial attachment, involvement with drug-using peers, and adolescent drug use: a longitudinal examination of mediational mechanisms. Psychology of Addictive Behaviors, 22 (2), 302-308.

Järvinen, M., \& Demant, J. (2011). The normalization of cannabis use among young people: symbolic boundary work in focus groups. Health, Risk \& Society, 13(2), 165-182.

Kandel, D.B. (1996). The parental and peer contexts of adolescent deviance: an algebra och interpersonal influences. Journal of Drug Issues, 26 (2), 289-315.

Karlsson, P. (2006). Margins of prevention. On older adolescents' positive and negative beliefs about illicit drug use. Stockholm: Stockholms universitet, institutionen för social arbete.

Koutakis, N., Stattin, H., \& Kerr, M. (2008). Reducing youth alcohol drinking through a parent-targeted intervention: the Örebro Prevention Programme. Addiction, 103, (10), 16291637.

Kuntsche, E., Knibbe, R., Gmel, G., \& Engels, R. (2005). Why do young people drink? A review of drinking motives. Clinical Psychology Review, 25, (7), 841-861.

Kuntsche, E., Knibbe, R., Gmel, G., \& Engels, R. (2006). Who drinks and why? A review of socio-demographic, personality, and contextual issues behind the drinking motives in young people. Addictive Behaviors, 31, (10), 1844-1857.
Ledoux, S., Miller, P., Choquet, M., \& Plant, M. (2002). Family structure, parent-child relationships, and alcohol and other drug use among teenagers in France and the United Kingdom. Alcohol \& Alcoholism, 37, (1), 52-60.

Lee, C.M., Neighbors, C., \& Woods, B.A. (2007). Marijuana motives: Young adults' reasons for using marijuana. Addictive Behaviors 32 (7), 1384-1394.

Lieberson, S., \& Lynn, F.B. (2002). Barking up with the wrong branch: scientific alternatives to the current model of sociological science. American Review of Sociology, 28, 1-19.

MacKinnon, D.P., Krull, J.L., \& Lockwood, C.M. (2000). Equivalence of the mediation, confounding and suppression effect. Prevention Science, 1 (4), 173-181.

Measham, F., \& Shiner, M. (2009). The legacy of "normalization". The role of classical and contemporary theory in understanding young people's drug use. International Journal of Drug Policy, 20, (6), 502-508.

Moffitt, T.E. (1993). Adolescence-limited and lifecourse-persistent antisocial behavior: a developmental taxonomy. Psychological Review, 100 (4). 674-701.

Moore, D. (2008). Erasing pleasure from public discourse on illicit drugs: on the creation and reproduction of an absence. International Journal of Drug Policy, 19(5), 353-358.

Mugford, S.K. (1994). Studies in the natural history of cocaine use - Theoretical afterword. Addiction Research, 2(1), 127-133.

Oetting, E.R., \& Donnermeyer, J.F. (1998). Primary Socialization Theory: The etiology of drug use and deviance. 1 Substance Use and Misuse, 33 (4), 995-1026.

Palmqvist, R.A., Martikainen, L.K., \& Rauste von Wright, M. (2003). A moving target: reasons given by adolescents for alcohol and narcotics use, 1984 and 1999. Journal of Youth and Adolescence, 32, (3), 195-203.

Parker, H. (2003). Pathology or modernity? Rethinking risk factor analyses of young drug users. Addiction Research \& Theory, 11 (3), 141-144. 
Parker, H., Aldridge, J., \& Measham, F. (1998). Illegal leisure. The normalization of adolescent recreational drug use. London: Routledge.

Pennay, A., \& Moore, D. (2010). Exploring the micro-politics of normalization: narratives of pleasure, self-control and desire in a sample of young Australian "party drug" users. Addiction Research \& Theory, 18(5), 557-571.

Petraitis, J., Flay, B.R., \& Miller, T.Q. (1995). Reviewing theories of adolescent substance use: organizing pieces in the puzzle. Psychological Bulletin, 117 (1), 67-86.

Poulin, F., Kiesner, J., Pedersen, S., \& Dishion, T.J. (2011). A short-term longitudinal analysis of friendship selection on early adolescent substance use. Journal of Adolescence, 34, (2), 249256.

Rhodes, T., Lilly, R., Fernández, C., Giorgino, E., Kemmesis, U.E., Ossebaard, H.C., Lalam, N., Faasen, I., \& Spannow, K.E. (2003). Risk factors associated with drug use: the importance of 'risk environment'. Drugs: Education, Prevention and Policy, 10(4), 303-329.

Robins, J.M., Hernán, M.Á., \& Brumback, B. (2000). Marginal structural models and causal inference in epidemiology. Epidemiology, 11, (5), 550-560.

Simons, J.S., Gaher, R.M., Correia, C.J., Hansen, C.L., \& Christopher, M.S. (2005). An affective motivational model of marijuana and alcohol problems among college students. Psychology of Addictive Behaviors, 19 (3), 326-334.

Simons-Morton, B. (2007). Social influences on adolescent substance use. American Journal of
Health Behavior, 31 (6), 672-684.

Skärstrand, E. (2010). Prevention of alcohol and drug problems among adolescents: evaluating a Swedish version of the Strengthening Families Program (diss.). Stockholm: Karolinska Institutet.

Smith, A., Thurston, M., Green, K. (2011). Propinquity, sociability and excitement: exploring the normalization of sensible drug use among 15-16-year olds in north-west England and north-east Wales. Journal of Youth Studies, 14 (3), 359-379.

Spooner, C. (2005). Structural determinants of drug use - a plea for broadening our thinking. Drug and Alcohol Review, 24, (2), 89-92.

Trzesniewski, K.H., \& Donnellan, M.B. (2010). Rethinking "Generation Me": A study of cohort effects from 1976-2006. Perspectives on Psychological Science, 5, (1), 58-75.

Twenge, J.M., \& Campbell, W.K. (2010). Birth cohort differences in the Monitoring the Future dataset and elsewhere: Further evidence for Generation Me - Commentary on Trzesniewski \& Donnellan (2010). Perspectives on Psychological Science, 5, (1), 81-88.

Velleman, R.D.B, Templeton, L.J., \& Copello, A.G. (2005). The role of the family in preventing and intervening with substance use and misuse: a comprehensive review of family interventions, with focus on young people. Drug and Alcohol Review, 24 (2), 93-109.

Warr, M. (1993). Parents, peers, and delinquency. Social Forces, 72 (1), 247-264. 


\section{Summary}

\section{Integrative aetiological analyses and drug prevention}

The importance of aetiological research for drug prevention is often recognized. This paper discusses the potential of theoretical integration of two opposing views of adolescent substance use. The first of these is referred to as "traditional" research where a common orientation is to identify various "deficits" that put the individual at risk of substance use. The other view is termed "modern" research where rational decisions located within a consumerist society are emphasized as a central explanation for substance use. This paper argues for the need for theoretically driven empirical studies that test the potential of integration, using Flay and Petraitis's (1994) integrative Theory of Triadic Influence as a structuring tool. A central argument deriving from the application of this theory is that variables from the two views sometimes can be assumed to reside in different causal "levels" but in the same causal chain, which has both theoretical and empirical impli- cations. Examples of potential models to empirically test are outlined. A methodologically oriented section stresses the very basic issue of recognizing the likelihood of so-called mediated or indirect effects in empirical tests of integrated models, drawing on research on the relationship between family factors, peers and adolescent drug use as an illustrative example. The potential of mediated effects implies that non-significant effects of some variables in multivariate models cannot by default be interpreted as if these variables are unrelated to the outcome. As is often stressed, controlling for a variable (e.g. a variable from "modern" drug research) will diminish the effect of a causally more distal variable (e.g. a variable from "traditional" drug research) if the former mediates the effect of the latter. Understanding this is crucial in order to not draw flawed conclusions in empirical studies with unifying ambitions. 